\title{
Dietary Effects of Punicic Acid on the Composition and Peroxidation of Rat Plasma Lipid
}

\author{
Chandrayana MukherJee, Sagarika Bhattacharyy, Santinath GHosh \\ and Dipak Kumar BHATTACHARYY* \\ Department of Chemical Technology, University Colleges of Science and Technology, Calcutta University \\ (92, A. P. C. Road, Kolkata-700009, West Bengal, INDIA)
}

Edited by H. Shimasaki, Teikyo Univ., and accepted March 18, 2002 (received for review January 21, 2002)

\begin{abstract}
The purpose of the present study is to examine the oxidative behavior of punicic acid (9 cis, 11 trans, 13 cis-18:3 octadecatrienoic fatty acid) under in vivo condition using male albino rats after blending with dietary soybean oil. Male weanling Charles Foster rats $(\mathrm{n}=$ four to eight), weighing 65-68 grams, were allocated for fourteen weeks to diets containing 0.6, 1.2 and $2.4 \%$ (by weight) punicic acid obtained from snake gourd seed oil (Trichosanthes anguina) after mixing with soybean oil, vis-à-vis control group consisting of $100 \%$ soybean oil, containing 50.3\% C18:2, 6.2\% 9 cis, 12 cis, 15 cis-18:3 (linolenic acid) and does not contain punicic acid. Increase in weight remained higher than control in rats fed with 0.6 and $1.2 \%$ punicic acid throughout the experimental period. There was significant lowering in plasma total cholesterol (TC) and low-density lipoprotein cholesterol (LDL-C) in the groups fed with $2.4 \%$ punicic acid. Lipoprotein oxidation susceptibility or LOS expressed as nmoles of malondialdehyde (MDA) per $\mathrm{mg}$ of non-high density lipoprotein cholesterol (non-HDL-C) and plasma lipid peroxidation or PLP expressed as nmoles of MDA per $\mathrm{ml}$ of plasma exhibited maximum antioxidant efficiency at $1.2 \%$ punicic acid, being equivalent to that of control (100\% soybean oil). While LOS expressed as nmoles of MDA decreased significantly (except at $2.4 \%$ punicic acid level) with the least oxidation at $0.6 \%$ punicic acid, with respect to control. Accordingly, punicic acid seemed to be acting both as pro-oxidant (at 1.2\% punicic acid level) and antioxidant (at $0.6 \%$ punicic acid level), with significant decrease in TC and LDL-C at 2.4\% punicic acid level when compared to control.
\end{abstract}

Key words: punicic acid, snake gourd, Trichosanthes anguina, lipoprotein oxidation susceptibility and plasma lipid peroxidation

\section{Introduction}

Punicic Acid is a conjugated trienoic fatty acid of the constitution cis-9-trans-11-cis-13-octadecatrienoic fatty acid. It is found in the seed fat of Snake gourd plant, Trichosanthes anguina, belonging to the natural order Cucurbitaceae. It maybe stated that the natives consume the fruits and seeds of the snake gourd plant mostly as vegetables. The seeds contain about $40-70 \%$ oil, with punicic acid content to be more or less equivalent to 40 $\%$ (1). Conjugated polyunsaturated fatty acids including conjugated linoleic acid (CLA) usually constitutes less than $1 \%$ in natural products or dairy products and it has been found to have antiatherosclerotic and anticarcinogenic effects owing to its antioxidant activity (2). Dhar et. al. has examined the oxidative behaviour of $\alpha$ elaeostearic acid obtained from the seed oil of karela, Momordica charantia, theoretically consisting of 33\%

\footnotetext{
* Correspondence to: Dipak Kumar Bhattacharyya, Department of Chemical Technology, University Colleges of Science and Technology, Calcutta University, 92, A. P. C. Road, Kolkata - 700009, West Bengal, INDIA

E-mail: peru_m234@caltiger.com
} 
cis and 66\% trans molecular composition and has claimed the antioxidant activity of the same in the plasma lipid of rats (3). No such study has been made incase of punicic acid, which has $66 \%$ cis and $33 \%$ trans configuration.

Punicic acid, a stereoisomer of $\alpha$-elaeostearic acid has melting point $43.5-44^{\circ} \mathrm{C}$ (4).

The present study is therefore specifically aimed to examine the oxidative behavior of punicic acid $(9 c, 11 t$, $13 c-18: 3$ conjugated fatty acid) considering its antagonistic cis-trans molecular arrangement with reference to $(\alpha$-elaeostearic acid $(9 c, 11 t, 13 t-18: 3$ conjugated fatty acid), after blending with soybean oil having non-conjugated octadecadienoic and octadecatrienoic fatty acids of all cis configuration, in the plasma lipid of male albino rats, under in vivo conditions.

\section{Experimental}

\subsection{Extraction from Dietary Fat Sources, Refining and Bleaching}

The fresh and ripe seeds of Trichosanthes anguina obtained from local market at "Sealdah", Calcutta, India, were grinded with anhydrous $\mathrm{Na}_{2} \mathrm{SO}_{4}$, extracted several times with solvent petroleum ether $\left(40^{\circ}-60^{\circ} \mathrm{C}\right.$, Analytical Reagent or AR and free from sulphur compounds) at room temperature. The extracts of the sample were filtered and concentrated by evaporation in vacuum. After removal of the solvent, dark reddish green oil having Free Fatty Acid (FFA) content of $3.58 \%$ was obtained. The FFA present was removed by using $10 \% \mathrm{NaOH}$ solution $(20 \%$ excess of the required theoretical amount). The refined oil was bleached with tonsil earth optimum $(1 \% \mathrm{w} / \mathrm{w})$, obtained from P.T. Sud-Chemic (Jakarta, Indonesia) and activated carbon $(0.5 \% \mathrm{w} / \mathrm{w})$, obtained from E. Merck India Pvt. Ltd., (Mumbai, India) at room temperature for 30 minutes. The oil was recovered by filtration and desolventised under vacuum at about $37^{\circ} \mathrm{C}$. The refined and bleached oil was flushed with nitrogen and stored in a refrigerator until further use.

\subsection{Characterization of the Oil}

The fatty acid compositions of the dietary oils were determined by converting the oils (triglycerides) into their methyl esters, separating them by thin layer chromatography (TLC) and finally analyzing them by gas liquid chromatography (GLC) techniques (5).
The position of punicic acid, cis-trans-cis isomer was identified by dissolving it in cyclohexane (analytical reagent or AR grade) and observed over wavelength range of 200-300 nm using a Shimadzu UV-Vis Spectrophotometer (Tokyo, Japan). The wavelengths 265.8, 275.6 and $286.8 \mathrm{~nm}$ corresponded to cis-trans-cis chromophore of punicic acid, respectively $(6,7)$.

The Infra Red (IR) Spectrum yielded two peaks at $932 \mathrm{~cm}^{-1}$ and $981 \mathrm{~cm}^{-1}$ corresponding absorptivity at $10.13 \mu$ and $10.67 \mu$ respectively, due to trans unsaturation of punicic acid $(8,9)$.

Punicic Acid is confirmed to be cis-9-trans-11-cis13-octadecatrienoic acid $\mathrm{CH}_{3} \cdot\left(\mathrm{CH}_{2}\right)_{3} \cdot \mathrm{CH}=\mathrm{CH} . \mathrm{CH}=\mathrm{CH}$. $\mathrm{CH}=\mathrm{CH} .\left(\mathrm{CH}_{2}\right)_{7} \cdot \mathrm{COOH}$.

The fatty acid compositions of the dietary oils were determined by converting the oils (triglycerides) into their methyl esters, according to the standard method of Litchfield (10), which were separated by TLC (Silica gel-G, $20 \times 20 \mathrm{cms}$, solvent system-hexane/ diethyl ether/ acetic acid-80:20:10, by vol.) according to the general procedure by Mangold (11). Finally the methylated fatty acids were separated and identified and were analyzed using GLC techniques in a Hewllet and Packard Model $5890 \AA$ with flame ionization detector and $\mathrm{N}_{2}$ as the carrier gas with flow rate of $30 \mathrm{ml}$ per minute, glass column 1/8 inch in diameter and six feet in length had been packed with $10 \%$ diethylene glycol succinate (DEGS). The oven, injection port and the detector block temperatures were maintained at 190 , 230 and $240^{\circ} \mathrm{C}$ respectively. About $0.1-1.0$ ( $\mu \mathrm{g}$ of sample was injected with the help of a Hamiltonian syringe, when the required chromatogram was obtained. The quantification of the fatty acids was done by comparing the retention time (RT) of GLC grade standard methyl esters of varying chain length and unsaturation (5). Fatty acid composition of the dietary oils and their blends are illustrated in Table $\mathbf{1}$

\subsection{Dietary Fat Blends}

Soybean oil, trade name Vital Refined Soybean Oil, SM Dyechem Ltd., SM Center, Mumbai, India, was mixed with $1.5,3.0$, and $6.0 \%$ Snake Gourd oil, contributing $0.6,1.2$ and $2.4 \%$ punicic acid respectively, along with a control consisting of $100 \%$ Soybean oil, so as to make the final concentration of $20 \%$ fat in the diet of each of the four groups. 


\subsection{Animals and Diet}

The animal experiments have been designed and carried out as per reports published from the laboratory earlier $(3,12)$. Thirty-two male albino rats were divided into four groups each of average body weight and kept in wire-bottomed cages of size $27 \times 21 \times 14 \mathrm{~cm}^{3}$, with free access to food and water. Male albino rats of Charles Foster strain were chosen for the experiment (13). Everyday rats were fed fresh water and diet ad libitum along with $20 \%$ fat, $55 \%$ starch, $18 \%$ casein, $3 \%$ cellulose, $4 \%$ salt mixture (Bernhart Tommarelli modified supplied by SISCO Research Laboratories Pvt. Ltd. Mumbai-400060, India.), along with one multivitamin and multimineral capsule per $\mathrm{kg}$ of diet; the composition of multivitamin capsule had been-vitamin A IP (as acetate) 10,000 IU, cholecalciferol IP (vitamin D3) 1,000 IU, thiamine mononitrate IP $10.0 \mathrm{mg}$, riboflavine IP $10.0 \mathrm{mg}$, pyridoxine hydrochloride IP 3.0 $\mathrm{mg}$, cyanacobalamin IP $15.0 \mathrm{mg}$, nicotinamide IP $100 \mathrm{mg}$, calcium pantothenate IP $16.3 \mathrm{mg}$, ascorbic acid IP $150.0 \mathrm{mg}, \alpha$-tocopheryl acetate IP $25.0 \mathrm{mg}$, biotin USP $0.25 \mathrm{mg}$; composition of multiminerals as followscalcium phosphate IP $129.0 \mathrm{mg}$, magnesium oxide light IP $60.0 \mathrm{mg}$, dried ferrous sulphate IP $32.04 \mathrm{mg}$, magnesium sulphate BP $2.03 \mathrm{mg}$, total phosphorus in the preparation $25.8 \mathrm{mg}$; trace elements were-copper sulphate IP $3.39 \mathrm{mg}$, zinc sulphate IP $2.20 \mathrm{mg}$, sodium molybdate $0.25 \mathrm{mg}$, sodium borate IP $0.88 \mathrm{mg}$. The diets were adequate in all nutrients. The amount of food consumed per day along with weekly increase in body weight was noted for each rat. The animals were maintained on their respective diets for 14 weeks. At the end of the feeding experiment the rats were kept fasting for 12 hours and sacrificed under mild anesthesia, blood was collected by heart puncture and after sealing properly, kept in the refrigerator until further analysis.

\subsection{Lipid Analysis in Plasma}

The estimations of Total Cholesterol or TC (14), Triglyceride or TG (15), High Density Lipoprotein Cholesterol or HDL-C $(16,17,18)$, and Low Density Lipoprotein Cholesterol or LDL-C (19) of plasma were carried out using enzymatic kits supplied by Span Diagnostics Ltd., Surat, India and Crest Biosystems, Goa, India. Plasma lipid peroxide was measured by the assay of thiobarbituric reactive substances (TBARS) according to the standard method (20). The amount of malondialdehyde (MDA) formed had been calculated taking the extinction coefficient of MDA as $1.56 \times 10^{5} \mathrm{M}^{-1}$ $\mathrm{cm}^{-1}$. Lipoprotein Oxidation Susceptibility Test (LOS) had been carried out by the precipitation of non-HDL$C$ i.e. apoB lipoproteins-LDL and Very Low Density Lipoprotein (VLDL) according to standard methods described by Phelps et al. (21).

\section{$2 \cdot 6$ Statistics}

Data are expressed as mean \pm standard error of mean (SEM). Comparison was made using the one-

Table 1 Fatty Acid Composition of Dietary Oils and Oil Blends.

\begin{tabular}{|c|c|c|c|c|c|c|}
\hline \multirow[b]{2}{*}{ Dietary Fat } & \multicolumn{6}{|c|}{ Fatty Acid Compositions ( $\%$ area $)^{\mathrm{a}}$} \\
\hline & $\mathrm{C}_{16: 0}$ & $\mathrm{C}_{18: 0}$ & $\mathrm{C}_{18: 1}$ & $\mathrm{C}_{18: 2}$ & $\mathrm{C}_{18: 3} \mathrm{~b}$ & $\mathrm{C}_{18: 3}^{\mathrm{c}}$ \\
\hline Snake gourd oil & 6.1 & 6.0 & 27.0 & 21.0 & 39.9 & - \\
\hline d Soybean oil & 11.7 & 2.9 & 28.8 & 50.3 & - & 6.2 \\
\hline $\begin{array}{c}{ }^{\mathrm{e}} \text { Soybean oil }+ \text { Snake gourd oil } \\
(98.5: 1.5, \mathrm{w} / \mathrm{w})\end{array}$ & 11.6 & 3.0 & 28.7 & 49.9 & 0.6 & 6.1 \\
\hline $\begin{array}{l}\text { f Soybean oil + Snake gourd oil } \\
(97: 3, \mathrm{w} / \mathrm{w})\end{array}$ & 11.5 & 3.0 & 28.8 & 49.4 & 1.2 & 6.0 \\
\hline $\begin{array}{l}{ }^{g} \text { Soybean oil }+ \text { Snake gourd oil } \\
(94: 6, \mathrm{w} / \mathrm{w})\end{array}$ & 11.4 & 3.1 & 28.7 & 48.5 & 2.4 & 5.8 \\
\hline \multicolumn{7}{|c|}{ a Obtained from gas liquid chromatography (GLC). } \\
\hline \multicolumn{7}{|c|}{ Punicic acid or conjugated linolenic acid of 9 cis, 11 trans, 13 cis-18:3 fatty acid configuration. } \\
\hline \multicolumn{7}{|c|}{${ }^{\mathrm{c}}$ Linolenic acid of 9 cis, 12 cis, 15 cis-18:3 fatty acid configuration. } \\
\hline \multicolumn{7}{|c|}{${ }^{\mathrm{d}}$ Control group A } \\
\hline \multicolumn{7}{|l|}{${ }^{\mathrm{e}}$ Experimental group B } \\
\hline \multicolumn{7}{|l|}{${ }^{\mathrm{f}}$ Experimental group $\mathrm{C}$} \\
\hline${ }^{\mathrm{g}}$ Experimental group D & & & & & & \\
\hline
\end{tabular}


way analysis of variance (ANOVA) followed by multiple comparison ' $\mathrm{t}$ ' test (22).

\section{Results and Discussion}

\section{$3 \cdot 1$ Body Weight Gain}

The mean body weight gain in rats fed with the $0.6 \%$ (group B), $1.2 \%$ (group C) and $2.4 \%$ (group D) $9 c, 11 t$, $13 c-18: 3$ (punicic acid) dietary groups for 14 weeks remained more or less steady, without much decline in trend (Fig. 1.). Smedman et al. also claimed that conjugated linoleic acid (CLA) had no major effects on body weight (23). But the increase in weight of the $1.2 \%$ (group C) and $0.6 \%$ (group B) punicic acid seemed to be higher than the control group A (soybean), throughout the experimental period. Dhar et al. showed evidence of improved body weight gain in rats fed with $\alpha$ eleostearic acid (3).

\subsection{Lipoprotein Oxidation Susceptibility or LOS in Plasma and Plasma Lipid Peroxidation or PLP}

LOS (nmoles of MDA) was found to increase with increase in the percentage of punicic acid with the maximum reduction in oxidative susceptibility at $0.6 \%$ punicic acid (group B) and the minimum reduction in oxidative susceptibility with $2.4 \%$ punicic acid (group D) as illustrated in Table 2. However, the overall statistical significance was obtained at $p<0.01$. On multiple ' $\mathrm{t}$ ' test comparison, significance (at $\mathrm{p}<0.01$ ) was obtained between the groups administered with dietary oils containing 1.2\% punicic acid (group C) and 2.4\% punicic acid (group D). Significance was further observed at $\mathrm{p}<0.01$ between experimental groups D (2.4\% punicic acid) and B $(0.6 \%$ punicic acid $)$ at $\mathrm{p}<$ 0.001 (Table 2). Thus maximum antioxidant activity was achieved with $0.6 \%$ punicic acid (group B).

When LOS expressed as nmoles of MDA per mg of non-HDL-C (Table 2), maximum antioxidant efficiency was obtained with control group A (soybean oil) followed by experimental groups $\mathrm{C}$ ( $1.2 \%$ punicic acid) and $\mathrm{B}(0.6 \%$ punicic acid $)$, while peroxidation reached its peak incase of group D (2.4\% punicic acid) (Table 2). In this case the statistical significance was obtained at $\mathrm{p}<0.01$ using ANOVA. On multiple ' $\mathrm{t}$ ' test comparison, significance was obtained at $p<0.001$ between

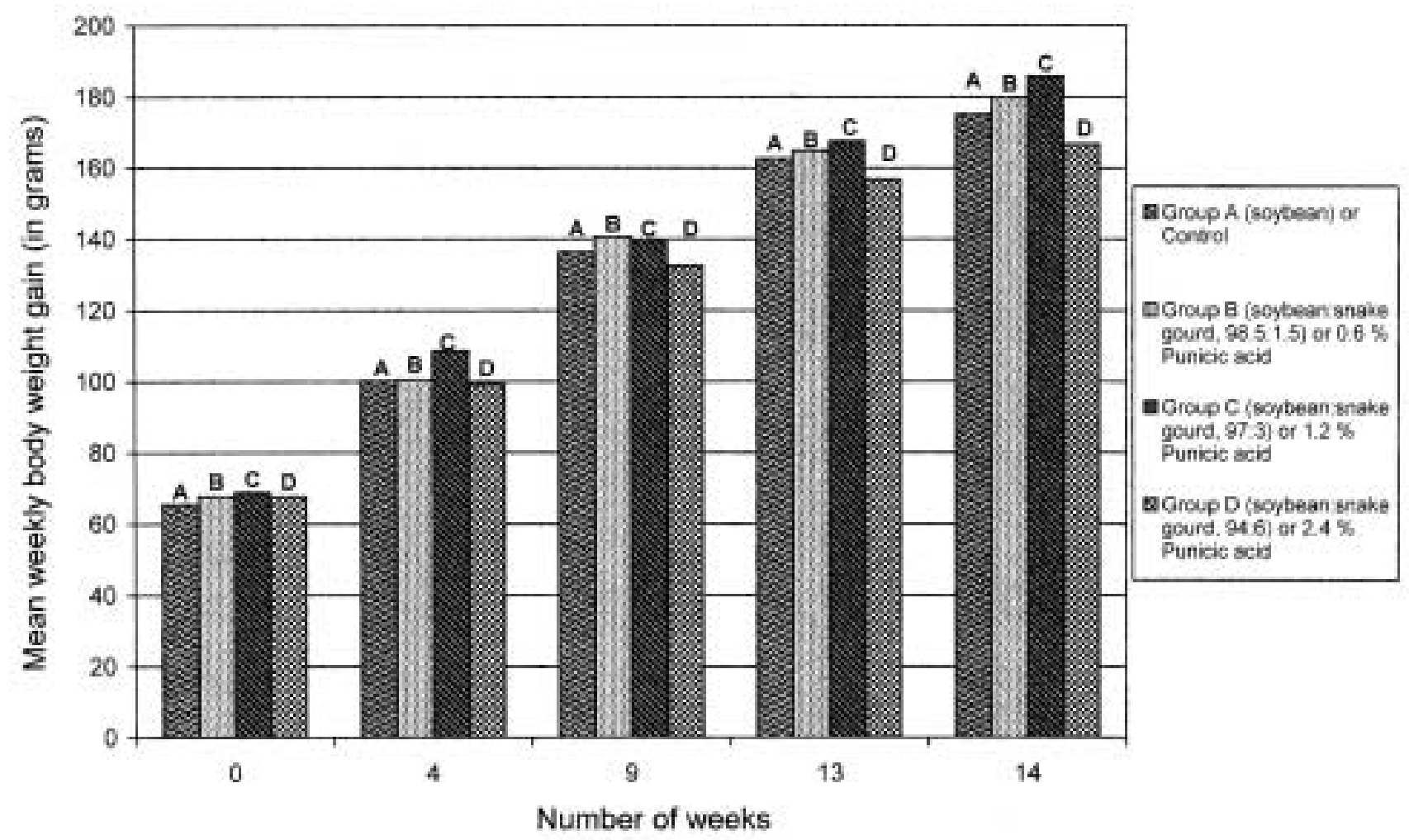

Fig. 1 Average Weekly Body Weight Gain in Rats Fed with the Dietary Oil Blends for 14 Weeks (n=4 to 8). 
Table 2 a LOS of Rats fed with Control and Experimental Dietary Oil Blends.

\begin{tabular}{lcr}
\hline $\begin{array}{l}\% \text { of Punicic Acid in } \\
\text { Dietary Oil Blends }\end{array}$ & $\begin{array}{l}\text { Lipoprotein Oxidation } \\
\text { Susceptibility (LOS) } \\
\text { (nmoles of MDA/ } \\
\text { mg of non-HDL Cholesterol) }\end{array}$ & $\begin{array}{r}\text { LOS } \\
\text { (nmoles of }\end{array}$ \\
\hline $0.0 \% 9 c, 11 t, 13 c-18: 3$ (group A or control) $^{\mathrm{b}}$ & $0.08 \pm 0.014^{\mathrm{c}, \mathrm{d}, \mathrm{e}}$ & $13.36 \pm 3.2^{\mathrm{c}, \mathrm{i}, \mathrm{j}}$ \\
$0.6 \% 9 c, 11 t, 13 c-18: 3$ (group B) $^{\mathrm{b}}$ & $0.16 \pm 0.008^{\mathrm{c}, \mathrm{e}, \mathrm{g}, \mathrm{h}}$ & $7.36 \pm 0.96^{\mathrm{c}, \mathrm{l}, \mathrm{j}}$ \\
$1.2 \% 9 c, 11 t, 13 c-18: 3$ (group C) $^{\mathrm{b}}$ & $0.1 \pm 0.0007^{\mathrm{c}, \mathrm{f}, \mathrm{g}}$ & $9.59 \pm 1.04^{\mathrm{c}, \mathrm{k}}$ \\
$2.4 \% 9 c, 11 t, 13 c-18: 3$ (group D) $^{\mathrm{b}}$ & $0.25 \pm 0.024^{\mathrm{c}, \mathrm{d}, \mathrm{f}, \mathrm{h}}$ & $20.67 \pm 2.93^{\mathrm{c}, \mathrm{k}, \mathrm{i}, \mathrm{l}}$ \\
\hline
\end{tabular}

${ }^{\text {a }}$ Expressed as means $\pm \mathrm{SEM} ; \mathrm{n}=$ four to eight rats per group.

${ }^{\mathrm{b}}$ Rats maintained on dietary blends containing $0.0 \%$ (group A or control oil), $0.6 \%$ (group B), 1.2\% (group C) and $2.4 \%$ (group D) punicic acid, respectively.

${ }^{\mathrm{c}}$ Denotes a significant difference with other numbers in the same column $(\mathrm{p}<0.01)$.

${ }^{\mathrm{d}}$ Significant difference with control and $2.4 \% 9 c, 11 t, 13 c-18: 3$ at $\mathrm{p}<0.001$.

${ }^{\mathrm{e}}$ Significant difference with control and $0.6 \% 9 c, 11 t, 13 c-18: 3$ at $\mathrm{p}<0.02$.

${ }^{\mathrm{f}}$ Significant difference with $1.2 \% 9 c, 11 t, 13 c-18: 3$ and $2.4 \% 9 c, 11 t, 13 c-18: 3$ at $\mathrm{p}<0.001$.

${ }^{\mathrm{g}}$ Significant difference with $1.2 \% 9 c, 11 t, 13 c-18: 3$ and $0.6 \% 9 c, 11 t, 13 c-18: 3$ at $\mathrm{p}<0.05$.

${ }^{\mathrm{h}}$ Significant difference with $2.4 \% 9 c, 11 t, 13 c-18: 3$ and $0.6 \% 9 c, 11 t, 13 c-18: 3$ at $\mathrm{p}<0.01$.

${ }^{\text {i }}$ Significant difference with control and $2.4 \% 9 c, 11 t, 13 c-18: 3$ at $\mathrm{p}<0.05$.

${ }^{\mathrm{j}}$ Significant difference with control and $0.6 \% 9 c, 11 t, 13 c-18: 3$ at $\mathrm{p}<0.1$.

${ }^{\mathrm{k}}$ Significant difference with $1.2 \% 9 c, 11 t, 13 c-18: 3$ and $2.4 \% 9 c, 11 t, 13 c-18: 3$ at $\mathrm{p}<0.01$.

${ }^{1}$ Significant difference with $2.4 \% 9 c, 11 t, 13 c-18: 3$ and $0.6 \% 9 c, 11 t, 13 c-18: 3$ at $\mathrm{p}<0.001$.

group A (control-soybean) and group D (2.4\% punicic acid); $p<0.02$ between control (group A) and group B ( $0.6 \%$ punicic acid); between group $C(1.2 \%$ punicic acid) and group D (2.4\% punicic acid) significance was obtained at $\mathrm{p}<0.001$, while that among group $\mathrm{D}$ (2.4 $\%$ punicic acid) and group B ( $0.6 \%$ punicic acid) it was $\mathrm{p}<0.01$. Thus maximum antioxidant activity (LOS expressed as nmoles of MDA per mg of non-HDL-C) among the experimental groups [0.6\% (group B), 1.2\% (group C) and 2.4\% (group D) punicic acid] was achieved with $1.2 \%$ punicic acid (group C) as evident from Table 2.

PLP expressed as nmoles of MDA per ml of plasma was maximally reduced with control, containing soybean oil (group A). This was nearly the same to that of $1.2 \%$ punicic acid (group $\mathrm{C}$ ), showing the maximum antioxidant efficacy with respect to other experimental groups (Fig. 2). No statistical significance was obtained.

UV spectrophotometric study of the plasma lipid of rats raised on $0.6 \%$ punicic acid (group B) showed absorbance at wavelengths ranging from 269.5 to 275 $\mathrm{nm}$, in cyclohexane solvent, suggesting the presence of conjugated trienoic fatty acid which maybe punicic acid or isomers of $\alpha$-elaeostearic acid; while that of $1.2 \%$ punicic acid (group C) at ( $\lambda_{\max } 230.0 \mathrm{~nm}$ maybe due to conjugated dienoic fatty acid. Spectrophotometric studies of plasma lipid of group B ( $0.6 \%$ punicic acid) show that some trienoic fatty acid in conjugated form might have been retained in plasma as evident from the UV spectra. According to Allen and Kummerow (24), the amount of triene conjugation lost and amount of diene conjugation formed are proportional to the amount of oxygen absorbed. Some conjugated dienoic fatty acids function by being prone to more rapid oxidation, picking up more free radicals, eliminating or reducing the formation of hydroperoxides. PLP (expressed as nmoles of MDA per ml of plasma) and LOS (expressed as nmoles of MDA per mg of non-HDL-C) were the least at $1.2 \%$ Punicic acid level (group C). In general, incase of PLP (expressed as nmoles of MDA per ml of plasma) and LOS (expressed as nmoles of MDA per mg of non-HDL-C) there appeared to have some dose-dependent protection at levels of $1.2 \%$ punicic acid, but no further beneficial effect was evident at levels above $1.2 \%$ punicic acid or below it (Fig. 2 and Table 2). Whereas, in the case of LOS (as nmoles of MDA) there appeared to be a dose-dependent protection at $1.2 \%$ punicic acid 


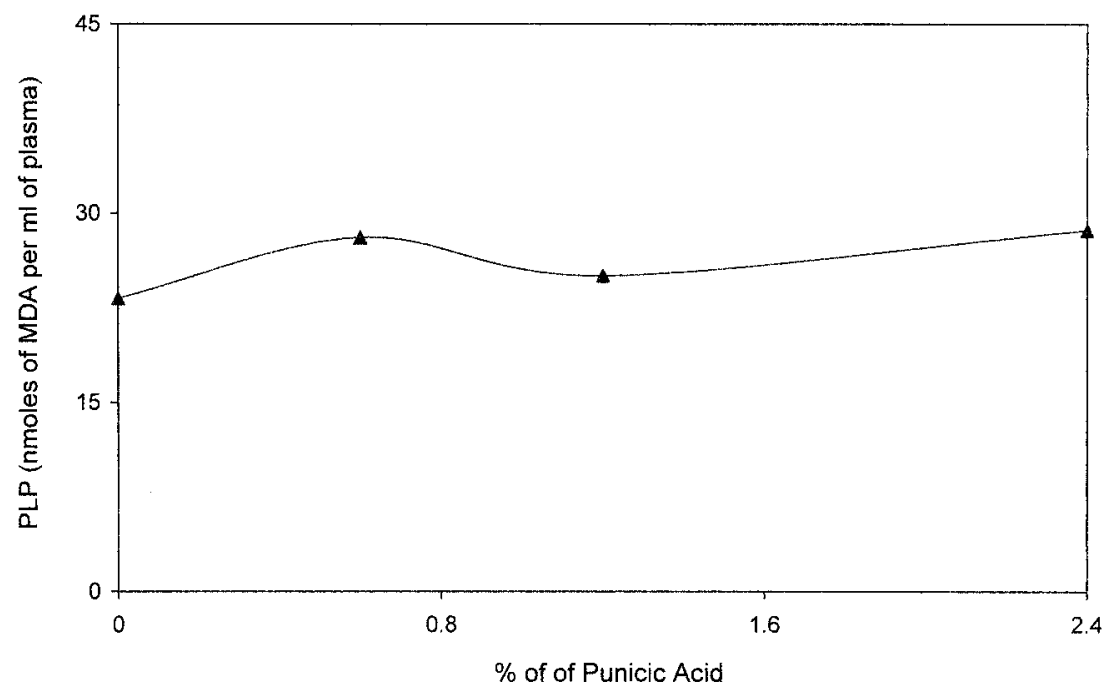

Fig. 2 PLP (nmoles of MDA per ml of plasma) in the Rats with respect to Increase in Percentage of Punicic Acid.

Each data point represents mean \pm standard error ( $n=4$ to 8 Rats).

$\boldsymbol{\Delta}$; plasma lipid peroxidation (nmoles of malonaldehyde per $\mathrm{ml}$ of plasma).

and below it, but no further beneficial effect was evident at levels above $1.2 \%$ punicic acid (Table 2). Thus, in vivo conditions the conjugated linolenic fatty acid, here punicic acid, might have inhibited the hydroperoxide formation by lowering free radical generation and peroxidation of PUFA (3). Another possible explanation may be that the biohydrogenation or free radical addition to one of the conjugated double bonds of punicic acid might have taken place, resulting in the formation of conjugated dienes that could have possibly acted as antioxidants (25). The possible mechanism involved in the hydroperoxide formation and biohydrogenation of punicic acid is thus illustrated in Scheme 1.

\subsection{Total Cholesterol, High Density Lipo- protein, Low Density Lipoprotein Cho- lesterol, Triglyceride (TG) and Very Low Density Lipoprotein (VLDL) in Plasma}

Total cholesterol (TC) in plasma of rats was the lowest when fed with $2.4 \%$ punicic acid (group D) and the highest when fed with $1.2 \%$ punicic acid (group C). It is found to be statistically significant at $\mathrm{p}<0.05$ (Table 3), as against $\alpha$-elaeostearic acid, where no significant difference in TC and various forms of cholesterol between experimental and control groups of rats was evidenced (3). This can also be attributed to the findings of Sambaiah et al., showing the degree of hydrogenation (saturation) of dietary unsaturated fatty acids in the fore stomach of ruminant animals by bacterial fermentation, which presumably led to increased formation of trans fatty acids of edible oils thus increasing its capacity to enhance serum cholesterol levels in a dose dependent manner (26).

As against the findings of $\alpha$-elaeostearic acid (3) high-density lipoprotein cholesterol (HDL-C) was the maximum with $0.6 \%$ punicic acid (group B) and minimum with $2.4 \%$ punicic acid (group D), when administered to rats in the diet, although HDL-C was predominant incase of control group A (100\% soybean oil). However no statistical significance was established (Table 3).

LDL-C was the maximum at $1.2 \%$ punicic acid (group C) and minima both at $2.4 \%$ (group D) and 0.6 $\%$ (group B) punicic acid. It is found to be statistically significant at $\mathrm{P}<0.01$, groups $\mathrm{A}$ (control) and $\mathrm{C}$ (1.2 $\%$ punicic acid) yielded significance at $p<0.01$, while significant values were obtained at $\mathrm{P}<0.001$ incase of experimental groups C (1.2\% punicic acid) and D (2.4 $\%$ punicic acid). Also, significant values were obtained at $\mathrm{P}<0.01$ incase of experimental groups $\mathrm{C}(1.2 \%$ punicic acid) and B (0.6\% punicic acid) (Table 3$)$. 


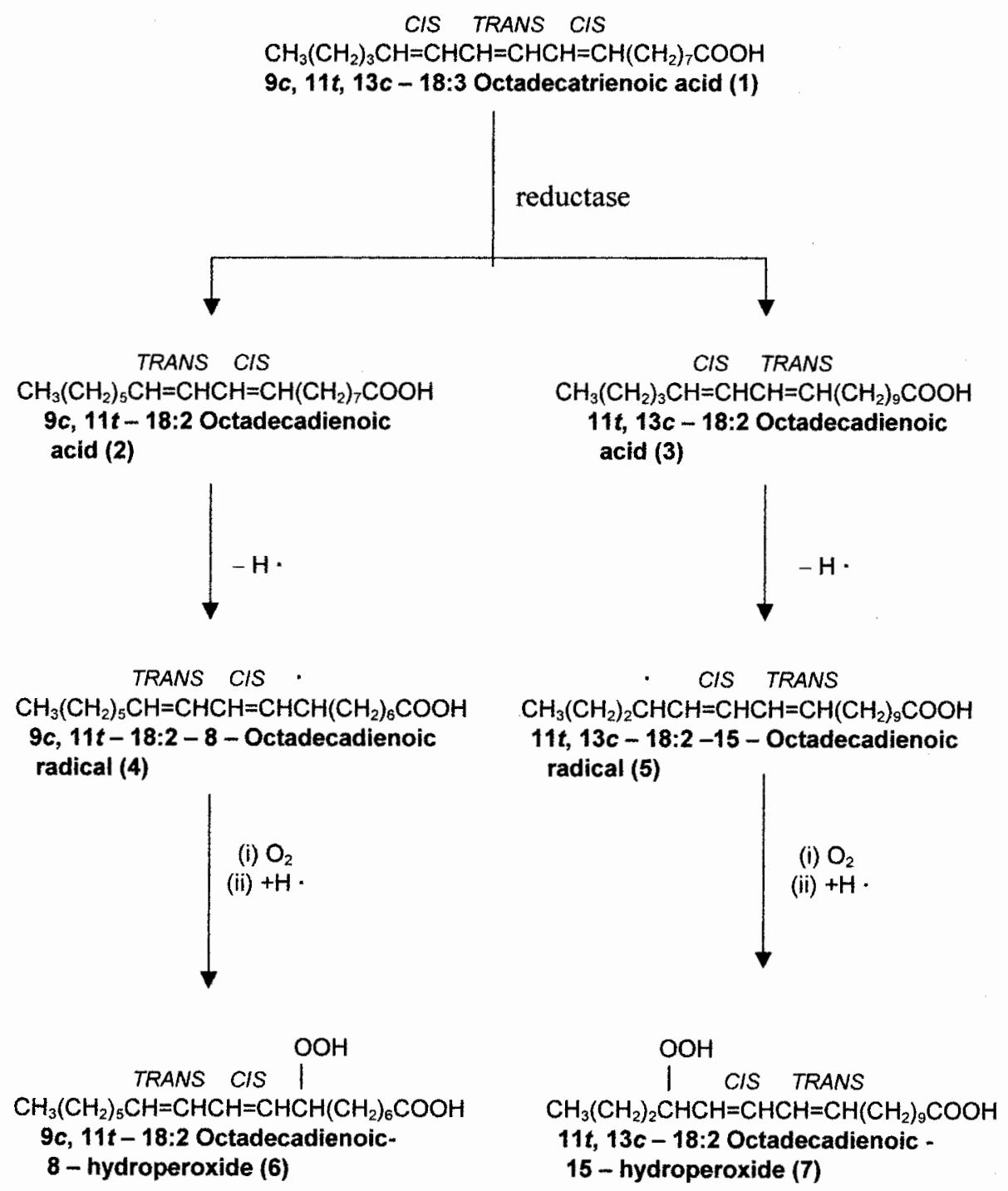

Scheme 1

Interestingly, the Atherogenic Index (AI) ratio [(TC /HDL-C)-1] was significantly $(\mathrm{p}<0.01)$ reduced at 0.6 $\%$ punicic acid (group B) and 2.4\% punicic acid (group D) levels respectively (Fig. 3). Though not significant, the same trend was observed in case of LDL-C to HDL$\mathrm{C}$ (LDL-C/HDL-C) ratio. It may be due to the fact that in punicic acid isomer the total cis and trans molecular configuration increased with increase in the amount of punicic acid from $0.6 \%$ in group B to $2.4 \%$ in group D through $1.2 \%$ in group C (Fig. 4).

Punicic acid when administered at 2.4\% level (group D) in the dietary blend lowered TC and LDL-C; similar findings were reported with conjugated linoleic acid (CLA) that lowered levels of TC and LDL-C in the blood of rabbits and hamsters (27).

TG and VLDL in plasma have lower values than the control with no statistical significance (Table 3).

These results may also be attributed to the increase in the cis configuration being $66 \%$ as against $33 \%$ trans in the conjugated molecule of punicic acid (the configuration of punicic acid being cis-trans-cis).

\section{Conclusion}

In conclusion, the present study unfolds the activity of $9 c, 11 t, 13 c-18: 3$ fatty acid (Punicic Acid) upon administration in the diet of rats at various concentrations. It is found to be efficient as an antioxidant (when 
Table 3 Plasma Lipid Profile of Rats fed Dietary Oil Blends Containing 0.0\% (group A), $0.6 \%$ (group B), $1.2 \%$ (group C), and 2.4\% (group D) Punicic Acid (Conjugated 9c,11t, 13c-18:3).

\begin{tabular}{lcccc}
\hline \multicolumn{1}{c}{${ }^{\mathrm{a}}$ Parameters } & ${ }^{\mathrm{b}}$ Group A & ${ }^{\mathrm{c}}$ Group B & ${ }^{\mathrm{d}}$ Group C & ${ }^{\mathrm{e}}$ Group D \\
\hline Total Cholesterol or TC (mg/dl) & $130.85 \pm 4.1^{\mathrm{f}}$ & $112.54 \pm 8.7^{\mathrm{f}, \mathrm{h}}$ & $153.81 \pm 13.7^{\mathrm{f}, \mathrm{g}, \mathrm{h}}$ & $109.50 \pm 11.6^{\mathrm{f}, \mathrm{g}}$ \\
Triglyceride or TG (mg/dl) & $88.34 \pm 13.0$ & $79.77 \pm 10.0$ & $78.4 \pm 12.5$ & $76.91 \pm 15.7$ \\
HDL-Cholesterol or HDL-C (mg/dl) & $42.70 \pm 4.6$ & $37.20 \pm 2.8$ & $33.37 \pm 2.7$ & $31.80 \pm 3.0$ \\
VLDL (mg/dl) & $17.67 \pm 2.6$ & $15.95 \pm 2.0$ & $15.68 \pm 2.5$ & $15.38 \pm 3.1$ \\
LDL-Cholesterol or LDL-C (mg/dl) & $66.53 \pm 4.7^{\mathrm{i}, \mathrm{j}}$ & $59.59 \pm 6.7^{\mathrm{i}, 1}$ & $100.18 \pm 11.8^{\mathrm{i}, \mathrm{j}, \mathrm{k}, 1}$ & $56.51 \pm 4.9^{\mathrm{i}, \mathrm{k}}$
\end{tabular}

${ }^{\text {a }}$ Expressed as means $\pm \mathrm{SEM} ; \mathrm{n}=$ four to eight rats per group.

${ }^{\mathrm{b}}$ Rats maintained on dietary oils containing $0.0 \%$ punicic acid.

${ }^{\mathrm{c}}$ Rats maintained on dietary oils containing $0.6 \%$ punicic acid.

${ }^{\mathrm{d}}$ Rats maintained on dietary oils containing $1.2 \%$ punicic acid.

${ }^{\mathrm{e}}$ Rats maintained on dietary oils containing $2.4 \%$ punicic acid.

${ }^{\mathrm{f}}$ Denotes a significant difference with other numbers in the same row $(\mathrm{p}<0.05)$.

${ }^{\mathrm{g}}$ Significant difference with $1.2 \%$ and $2.4 \%$ punicic acid at $\mathrm{p}<0.01$.

${ }^{\mathrm{h}}$ Significant difference with $1.2 \%$ and $0.6 \%$ punicic acid at $\mathrm{p}<0.02$.

${ }^{\mathrm{i}}$ Denotes a significant difference with other numbers in the same row $(\mathrm{p}<0.01)$.

${ }^{j}$ Significant difference with control and $1.2 \%$ punicic acid at $\mathrm{p}<0.01$.

${ }^{\mathrm{k}}$ Significant difference with 1.2 and $2.4 \%$ punicic acid at $\mathrm{p}<0.001$.

${ }^{1}$ Significant difference with 1.2 and $0.6 \%$ punicic acid at $\mathrm{p}<0.01$.

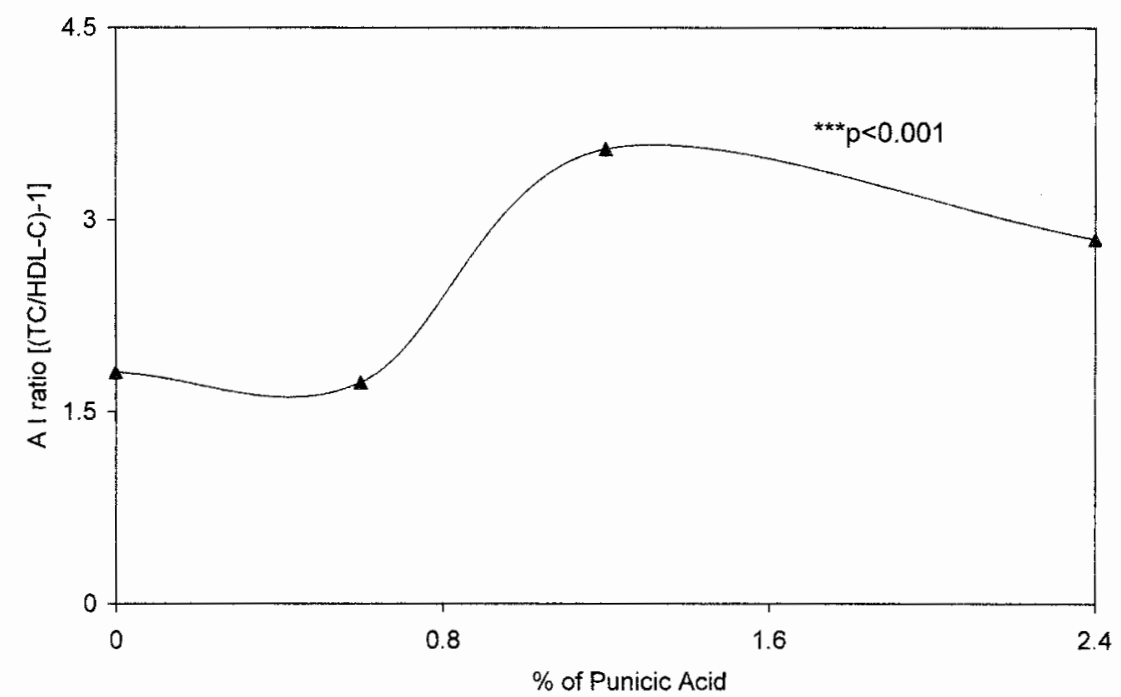

Fig. 3 AI ratio [(TC/HDL-C)-1] in the Plasma of Rats with respect to Increase in Percentage of Punicic Acid.

Each data point represents mean \pm standard error ( $n=4$ to 8 Rats).

$\boldsymbol{\Delta}$; atherogenic index ratio [(total cholesterol/high density lipoprotein cholesterol)-1].

*** Significant difference between control (group A) and three experimental groups (B, C, and D consisting of $0.6 \%, 1.2 \%$ and $2.4 \% 9 c, 11 t, 13 c-18: 3$ conjugated fatty acid respectively) at $\mathrm{p}<0.01$, by one way ANOVA followed by multiple comparison ' $\mathrm{t}$ ' test, between groups $\mathrm{A}$ and $\mathrm{D}$ at $\mathrm{p}<0.02$, between groups $\mathrm{C}$ and $\mathrm{B}$ at $\mathrm{p}<0.01$, between groups $\mathrm{D}$ and $\mathrm{B}$ at $\mathrm{p}<0.01$. 


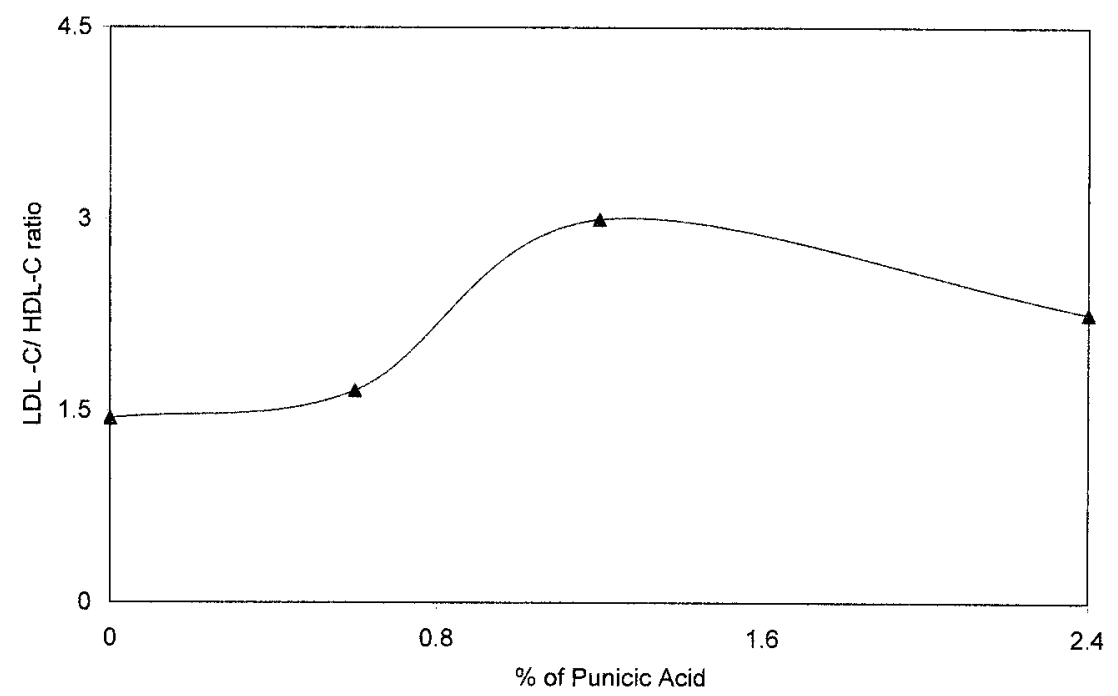

Fig. 4 LDL-C/HDL-C ratio in the Plasma of Rats with respect to Increase in Percentage of Punicic Acid.

Each data point represents mean \pm standard error ( $n=4$ to 8 Rats).

$\boldsymbol{\Delta}$; low density lipoprotein cholesterol /high density lipoprotein cholesterol ratio.

expressed as nmoles of MDA) both at $0.6 \%$ (group B) and $1.2 \%$ levels (group $\mathrm{C}$ ) but is found to be a marginal prooxidant at $1.2 \%$ level (group C) (when expressed as nmoles of MDA/mg of non-HDL cholesterol and nmoles of MDA $/ \mathrm{ml}$ of plasma). There is significant decrease in TC and LDL-C at $2.4 \%$ level (group D), accompanied by a significant decrease in LDL /HDL and atherogenic index (AI) ratio at $0.6 \% 9 c, 11 t, 13 c$ 18:3 conjugated fatty acid (group B) concentrations. The dietary groups were nutritionally equivalent, and the PUFA content of the four dietary groups were more than adequate, almost equal in content, and the percentage of punicic acid were low.

\section{Acknowledgements}

The first author is thankful to the Council of Scientific and Industrial Research (CSIR), New Delhi for the financial support rendered by awarding a Senior Research Fellowship (vide 9/28(521)/2000-EMR I), and also to Lady Tata Memorial Trust, Mumbai for funding a part of the project by awarding a Junior Research Fellowship (1998 August-2000 August). We are very much indebted to Ms. Kabita Dutta for her help in maintaining the animals. We are also thankful to Prof. P. Chaudhuri of Indian Statistical Institution, Kolkata for helping in doing the statistical calculations.

\section{References}

1. Takagi, T. and Itabashi, Y. (1981) Lipids, 16, 546-551.

2. Suzuki, R., Noguchi, R., Ota, T., Abe, M., Miyashita, K. and Kawada, T. (2001) Lipids, 36, 477-482.

3. Dhar, P., Ghosh, S. and Bhattacharyya, D.K. (1999) Lipids, 34, 109-114.

4. Toyama, Y. and Tsuchiya, T. (1935) J. Soc. Chem. Ind. Japan, 38, 182B-185B.

5. Ghosh Chaudhuri, P., Chakrabarty, M.M. and Bhattacharyya, D.K. (1983) Fette. Seifen. Anstrichm., 85, 224-227.

6. Lakshminarayana, G., Kaimal, J.N.B., Mani, V.V.S., Sita Devi, K. and Chandrashekara Rao, T. (1982) Photochemistry, 21, 303305.

7. Chisholm, M.J. and Hopkins, C.Y. (1962) J. Org. Chem., 27, 3137-3139.

8. O’Connor, R.T. (1961) J. Am. Oil Chem. Soc., 38, 648-659.

9. Hussain, S. and Sita Devi, K. (1993) Lipids, 28, 1037-1040.

10. Litchfield, C. (1972) Analysis of Triglycerides, Academic Press, New York, pp. 17-35.

11. Mangold, H. (1969) Thin Layer Chromatography, Springer-Verlag, Berlin, p. 377.

12. Sarkar, S. and Bhattacharyya, D.K. (1991) J. Am. Oil Chem. Soc., 68, 956-962.

13. Ray, S. and Bhattacharyya, D.K. (1995) J. Am. Oil Chem. Soc., 72, 327-330.

14. Wybenga, D.R., Pileggi, V.J., Dirstine, P.H. and Di Giorgio, J. 
(1970) Clin. Chem., 16, 980-984.

15. Bucolo, G. and David, H. (1973) Clin. Chem., 19, 476-482.

16. Warnick, G.R., Nguyen, T. and Albers, A.A. (1985) Clin. Chem., 31, 217.

17. Burstein, M., Scholnick, H.R. and Morfin, R. (1970) J. Lipid Res., 11, 583-595.

18. Warnick, G.R., Cheung, M.C. and Albers, J.J. (1979) Clin. Chem., 25, 596.

19. Frieldewald, W.T., Levy, R.I. and Fridrickson, P.S. (1972) Clin. Chem., 18, 499-502.

20. Wills, E.D. (1987) Biochemical Toxicology, A Practical Approach, IRL Press, Oxford, pp. 127-151.
21. Phelps, S. and Harris, W.S. (1993) Lipids, 28, 475-477.

22. Das, D. and Das, A. (1998) Statistics in Biology and Psychology, 3rd edn, Academic Publishers, Calcutta, pp. 250-282.

23. Smedman, A. and Vessby, B. (2001) Lipids, 36, 773-781.

24. Allen, R.R. and Kummerow, F.A. (1951) J. Am. Oil Chem. Soc., 28, 101-105.

25. Ip, C., Scimeca, J.A. and Thompson, H.J. (1994) Cancer, 74 (suppl), 1050-1054.

26. Sambaiah, K. and Lokesh, B.R. (1999) Indian Jr. of Biochem. Biophy., 36, 211-220.

27. Steinhart, C. (1996) J. Chem. Educ., 73, A302. 